\title{
A PRESCRIPTION PATTERN STUDY OF RESPIRATORY TRACT INFECTIONS IN PAEDIATRIC INDOOR PATIENTS IN A TERTIARY CARE TEACHING HOSPITAL - A PROSPECTIVE OBSERVATIONAL STUDY
}

\author{
VANDANA BADAR, VIDISHA PARULEKAR, PRITI GARATE
}

Department of Pharmacology, Indira Gandhi Government Medical College, Nagpur, Maharashtra, India. Email: drvandanabadar@yahoo.co.in Received: 30 January 2018, Revised and Accepted: 30 March 2018

\section{ABSTRACT}

Objectives: The objectives of the study were as follows: (1) To study the prescription patterns in Respiratory tract infections (RTI) in indoor patients in pediatric wards. (2) To check the rationality of treatment according to Modified Kunin's rationality criteria. (3)To analyze the data of RTI by Anatomical Therapeutic Chemical classification.

Methods: It was a non-interventional, prospective, observational study which was conducted in indoor pediatric patients in a tertiary care teaching hospital in India. Data were analyzed and evaluated according to the WHO rational use of drugs guidelines.

Study sample: The study sample was 174 .

Study duration: The study duration was August 15, 2016-September 15, 2016.

Results: Males (63.79\%) were more as compared to females (36.20\%), and the highest number of cases was seen in infants (62.06\%). Acute bronchiolitis (54.02\%) was highest in the incidence followed by Wheeze Associated Lower Respiratory Tract Infection (WALRI) (30.45\%). The average duration of patient stay in hospital was 4.71 days whereas $93.33 \%$ were polytherapy and mostly prescribed antibiotic was amoxicillin-clavulanic acid in acute bronchiolitis and WALRI. Salbutamol (40.84\%) and Ipratropium Bromide (39.43\%) were the commonly prescribed respiratory medicines. Oral route $(42.27 \%)$ was the most common route of administration. $56.11 \%$ drugs were prescribed by generic name.

Conclusion: Standard treatment guidelines for the treatment of RTI need to be urgently developed and strictly implemented.

Keywords: Antibiotics, Infants, Modified Kunin's rationality criteria, Anatomical Therapeutic Chemical classification.

(C) 2018 The Authors. Published by Innovare Academic Sciences Pvt Ltd. This is an open access article under the CC BY license (http://creativecommons. org/licenses/by/4. 0/) DOI: http://dx.doi.org/10.22159/ajpcr.2018.v11i7.24407

\section{INTRODUCTION}

Infants and children are the most vulnerable population to contract the illness, and the antimicrobial agents are commonly used to treat this illness [1,2]. Acute respiratory infections are the leading cause of death in young children resulting in 1.9 million childhood death per year in developing countries, $20 \%$ of these deaths are from India [1]. Acute respiratory tract infections can be classified as upper respiratory tract infections and lower respiratory tract infections (LRTI). LRTI include acute bronchitis, bronchiolitis, and pneumonia. Acute respiratory infections are the most common cause of clinician consultation in pediatric age group [3]. The underlying etiology is viral, hence does not always require an antibiotic prescription. However, antibiotics are often used for the treatment of acute respiratory infection episodes including non-specific symptoms such as sore throat, common cold, and rhinitis for which there is an unlikely therapeutic benefit [4] because LRTIs are major reasons for antimicrobial agents, AMAs utilization and changes in AMAs resistance pattern are threat to its effective treatment, there is increasing concern about AMAs prescription in community [5]. In the recent years, studies on drug utilization have become a potential tool to be used in the evaluation of health systems [6]. Inappropriate use of AMAs for non-bacterial infections and for self-limiting clinical conditions is a major concern, so this study was planned with the aims and objectives to study the prescription patterns in RTI in patients in pediatric wards and to check rationality according to Modified Kunin's rationality criteria, to analyze the data of RTI receiving antibiotics by Anatomical Therapeutic Chemical (ATC) Classification.

\section{METHODS}

It is a non-interventional, prospective, observational study conducted in a tertiary teaching care hospital in India. Institutional Ethics Committee permission was taken (Reg. No. ECR/485/Inst/MH/2013) and the data of indoor case ticket of the pediatric patients were collected after taking written informed consent from parents of patients. Data were analyzed and evaluated with the help of the WHO rational use of drugs indicators. 174 pediatric cases were taken, and 235 prescriptions were studied for the period of 1 month (August 15 2016- September $152016)$. The patients included in the study were of the pediatric group (birth - 12 years), of either gender, diagnosed cases of LRTI, indoor patients. Exclusion criteria were outpatients, critically ill patients, patients with anti-tubercular therapy, and patients having other systemic illness (gastrointestinal infections, central nervous system infections, and hepatorenal diseases).

Following parameters were analyzed.

1. Demographic characters (age, sex, diagnosis, and immunization status).

2. WHO rational use of drugs indicators - prescribing indicators.

a. Average number of drugs per prescription (dose, route, and duration).

b. Percentage of drugs prescribed by generic name.

c. Percentage of AMAs prescribed per patient per prescription (dose, route, and duration).

d. Percentage of drugs given by injections.

e. Percentage prescribed from National List of Essential Medicines or formulary.

f. Total hospital stay. 
3. Analysis of the group-wise distribution of drugs.

4. ATC classification.

5. Analysis of treatment according to modified Kunin's rationality criteria.

\section{Statistical methods}

Data collected were subjected to descriptive statistical analysis using Microsoft Excel 2010 and GraphPad InStat version 3.10. Results were given in numbers and percentages. Chi-square test was applied to demographic characteristics and number of drugs and number of antibiotics per patient per prescription was studied and was expressed in mean \pm standard deviation (SD) with respect to the previous similar studies. Significance levels were set at $\mathrm{p}<0.05$.

\section{RESULTS}

In our study, 174 patients were enrolled, and 235 prescriptions were studied, and the results are given in numbers, percentages, Chi-square test was applied, and data were expressed as mean \pm SD. According to the demographic characteristics, it is clearly evident that in this study, a number of males (64\%) are more than that of females $(36 \%)$ ratio being $2: 1$. In our study, the mean age of the pediatric patients was 22.60 months ( 1 year, 10 months) and the range was birth to 12 years.

According to immunization status (71.83\%), children were completely immunized, $10.34 \%$ were partially immunized, $4.59 \%$ were unimmunized, and $13.21 \%$ of children's immunization status were unknown. The most common presenting complaints were cough, breathlessness, runny nose, and fever. The common investigations done were complete blood count and chest X-ray, four common diagnoses were considered of which most common acute bronchiolitis (54\%) followed wheeze associated lower respiratory tract infection (WALRI) (31\%), pneumonia (10\%), and hyperactive airway disease (5\%).

Applying statistical test to the demography, the most common diagnosis is acute bronchiolitis and seen most commonly in infant age group which is Chi-square significant with Chi-square value (23.53).

The WHO prescribing parameters such as average number of drugs per encounter, percentage of encounters with antibiotic, or with injection are described in Table 1.

Mostly polytherapy was followed (93.33\%). 3-4 drugs were prescribed in $39.99 \%$ of patients. (Table 2 ).

Single antibiotic therapy was followed in $77.87 \%$ patients (Table 3 ).

Antibiotics (33\%), antipyretics (32\%), and $\beta_{2}$ agonists (32\%) were most common class of drugs used for treating RTI. Most common antipyretic was paracetamol and salbutamol (40.84\%) and ipratropium bromide (39.43\%) being most common bronchodilator.

According to antibiotics, prescribed as per diagnosis, amoxicillinclavulanic is most common antibiotic given in cases of acute bronchiolitis $(43.38 \%)$ and WALRI (50\%), cefotaxime and sulfamethoxazoletrimethoprim combination in pneumonia (77.27\%), and hyperactive airway disease $(100 \%)$, respectively.

Most common route of administration is oral (42.27\%) followed by inhalational (24.59\%), intravenous (23.20\%), and topical $(0.7 \%)$.

Out of total drugs prescribed, $56.11 \%$ drugs were prescribed by generic name.

Table 4 shows drugs given according to ATC classification revealed that amoxicillin-clavulanic acid, amoxicillin, and cefotaxime were most commonly prescribed antimicrobial agents in infants. Irrational fixeddose combinations (cough and cold preparations) were used in very few patients

The average duration of hospital stay was 4.31 days. (3-7days).
Table 1: WHO prescribing indicators

\begin{tabular}{ll}
\hline Indicator value & Values (\%) \\
\hline Average number of drugs per encounter & 4.39 \\
Percentage of drugs prescribed from NLEM & 38 \\
Percentage of drugs prescribed by generic name & 56.12 \\
Percentage of encounters with an injection & 23.20 \\
prescribed & \\
Percentage of encounters with antibiotic prescribed & 98.29 \\
\hline
\end{tabular}

NLEM: National List of Essential Medicines

Table 2: Drugs prescribed/patient/prescription

\begin{tabular}{ll}
\hline Drugs prescribed/patient/prescription & $\mathbf{n}(\mathbf{\%})$ \\
\hline 1 & $17(7.23)$ \\
2 & $20(8.51)$ \\
3 & $50(21.27)$ \\
4 & $44(18.72)$ \\
5 & $47(20)$ \\
6 & $20(8.51)$ \\
7 & $14(5.95)$ \\
8 & $8(3.40)$ \\
9 & $9(3.82)$ \\
10 & $6(2.55)$ \\
Total & $235(100)$ \\
\hline
\end{tabular}

Table 3: Number of antibiotics prescribed/patient/prescription

\begin{tabular}{ll}
\hline $\begin{array}{l}\text { Number of antibiotics prescribed/ } \\
\text { patient/prescription }\end{array}$ & $\mathbf{n}(\%)$ \\
\hline 1 & $183(77.87)$ \\
2 & $36(15.31)$ \\
3 & $10(4.25)$ \\
4 & $4(1.70)$ \\
5 & $2(0.85)$ \\
Total & $235(100)$ \\
\hline
\end{tabular}

According to modified Kunin's criteria, 77\% were in category I, and they received rational treatment. Table 5 showed very few irrational prescriptions.

\section{DISCUSSION}

The present study was done to evaluate drug utilization pattern among pediatric inpatients of 174 cases records and 235 prescriptions of LRTI. There was a preponderance of male patients [9], and the ratio of male to female was $2: 1$. Infant and children represent a large part of the population in developing countries [10]. In our study, the mean age of pediatric patient was 1.1 years, and the range was from birth to 12 years. The immunization status showed that $71.83 \%$ patients were adequately immunized as per their age. The average duration of a patient staying in hospital wards was 4.3 days whereas in the study of Jose et al., [11] the duration of hospital stay was 5-6 days and was 3.8 with Pasha et al [12]. Acute bronchiolitis was most common in 54\% cases following WALRI in 31\% cases whereas in the study of Shruthi et al.,[13] it was observed that bronchopneumonia as most common diagnosis and bronchiolitis being the second most common and in Joes et al. it was observed that bronchopneumonia as the most common diagnosis followed by WALRI and bronchiolitis. Average number of drugs per patient is an important index of the prescription audit. Mean number of drugs per prescription should be kept as low as possible. The WHO recommends that the average number of drugs per prescription should be $<2$ [14]. Average number of drugs prescribed per case was $4.39 \pm 2.21$. It could be due to the study of indoor patients admitted due to LRTI. In Triruthopu et al. study showed an average number of drugs per prescription was 4.56 which is more than present study [15]. Higher figures (polypharmacy) always lead to increase the risk of drug interactions, adverse effects, development of bacterial resistance, and 
Table 4: Drugs prescribed according to ATC classification [7]

\begin{tabular}{|c|c|c|c|c|c|}
\hline \multicolumn{6}{|l|}{ Drugs prescribed according to ATC classification $(n=711)$} \\
\hline \multirow{2}{*}{$\frac{\text { Drugs (ATC Classification) }}{\text { I. Antimicrobials (J01) }}$} & \multicolumn{4}{|c|}{ Age groups (in years) } & \multirow[t]{2}{*}{ Total } \\
\hline & $\leq 1$ & $>1-<5$ & $\geq 5-8$ & $9-12$ & \\
\hline Amoxicillin (J01CA04) & 25 & 10 & 9 & 2 & 46 \\
\hline Cefotaxime (J01DD01) & 18 & 12 & 8 & 7 & 45 \\
\hline Gentamycin (J01GB03) & 2 & 5 & 6 & 4 & 17 \\
\hline Azithromycin (J01FA10) & 6 & 1 & 2 & 2 & 11 \\
\hline Amikacin (J01GB06) & 1 & 0 & 4 & 1 & 06 \\
\hline Cefixime (J01DD08) & 0 & 0 & 2 & 1 & 03 \\
\hline Sulfamethoxazole- trimethoprim (J01EE01) & 0 & 3 & 4 & 2 & 09 \\
\hline \multicolumn{6}{|l|}{ II. Respiratory System } \\
\hline \multicolumn{6}{|l|}{ a. Nasal preparations (R01) } \\
\hline Ipratropium bromide (R01AX03) & 116 & 32 & 25 & 17 & 189 \\
\hline b. Corticosteroids (R01AD) Hydrocortisone (R01AD60) & 1 & 5 & 1 & 4 & 11 \\
\hline \multicolumn{6}{|l|}{ Budesonide (R01AD05) Dexamethasone (R01AD53) } \\
\hline Salbutamol (R03AC02) & 106 & 60 & 27 & 28 & 221 \\
\hline Levosalbutamol+Ipratropium bromide (R03AH) & - & 2 & - & - & 2 \\
\hline $\begin{array}{l}\text { Aminophylline (R03DA55) Deriphyllin } \\
\text { d. Cough and cold preparations }\end{array}$ & - & 4 & 1 & - & 5 \\
\hline Antihistaminic+Antitussive+Decongestant* & - & 5 & 11 & 3 & 19 \\
\hline III. Antipyretics (N02) Paracetamol (N02BE01) & 119 & 67 & 19 & 25 & 233 \\
\hline
\end{tabular}

*Irrational fixed-dose combinations. OAD: Obstructive airway disease

Table 5: Appropriateness of the AMAS prescribed by modified Kunin's criteria [8]

\begin{tabular}{ll}
\hline Kunin's criteria (n=174) & $\mathbf{n}(\mathbf{\%})$ \\
\hline $\begin{array}{l}\text { Criteria I - Agree with the use of antimicrobial therapy, } \\
\text { the protocol is appropriate }\end{array}$ & $105(77)$ \\
$\begin{array}{l}\text { Criteria II - Agree with the use of antimicrobial } \\
\text { therapy, the protocol is probably appropriate, but a }\end{array}$ & $36(20.68)$ \\
$\begin{array}{l}\text { microbiology report is missing, to classify the protocol } \\
\text { in another category }\end{array}$ & $19(10.91)$ \\
$\begin{array}{l}\text { Criteria III - Agree with the use of antimicrobial } \\
\text { therapy, but a different antimicrobial is preferred }\end{array}$ & $6(3.44)$ \\
$\begin{array}{l}\text { Criteria IV - Agree with the use of antimicrobial } \\
\text { therapy, but a modified dose, interval, duration or } \\
\text { route of administration is preferred } \\
\text { Criteria V - Disagree with the use of antimicrobial } \\
\text { therapy, administration is unjustified }\end{array}$ & $8(4.59)$ \\
\hline
\end{tabular}

increase hospital cost [16].

Single antibiotic therapy was prescribed in most of the prescriptions (77.87\%) which is similar to the study done by Mohapatra et al.[17] and Arute et al. [18] and the average number of antibiotics per prescriptions was $1.25 \pm 0.62$. In our study, according to antibiotics prescribed as per the diagnosis, amoxicillin-clavulanic acid was most common antibiotic given in cases of acute bronchiolitis and WALRI whereas cefotaxime and sulfisoxazole and trimethoprim combination in pneumonia and hyperactive airway disease, respectively, which is similar to Shruthi et al. [13].

More common drugs used other than antimicrobial agents were paracetamol, salbutamol, and ipratropium bromide $(36.70 \%)$ whereas in the study of Pramil et al. stated $21 \%$ of all prescribed drugs were analgesics and antipyretics, i.e. ibuprofen and paracetamol as paracetamol are proven and safe antipyretic [19].

Most of the drugs were prescribed by generic name (56.11\%) which was inconsistent with Kumar et al. study where encounters with brand name were $100 \%$ [20] Prescribing by generic name is known to reduce the confusion and cost of the drug treatment and to rationalize drug therapy. This varies from 13.3 to $93 \%$ across the globe [21].

In our study, 90.43\% drugs were prescribed from Essential medicine list (EML). Drug prescription from EML is beneficial in terms of costeffectiveness and safety of drugs [22].

In this study, most of the patients received oral medicines, and the antibiotics and antipyretics prescribed by oral route were $42.27 \%$ and by injectable route were $23.20 \%$ and by inhalational route $(33.75 \%)$. The WHO recommends the lesser use of injections as it is helpful in reducing the cost of treatment and its disadvantages such as increased chances of infection, air embolism and thus increasing morbidity and mortality [23]. In oral dosage forms most commonly used dosage form was syrup. Pediatric patients have good compliance with syrups and drops than tablets and capsules. This helps in completing the treatment regimen.

Salbutamol, ipratropium bromide, and budesonide were most common drugs given by inhalational route $(24.59 \%)$. Drugs given by this route produce a rapid effect and provide symptomatic relief [23] and are devoid of systemic adverse effects.

The appropriateness of the AMAs prescribed was assessed by modified Kunin's criteria [8,24] (Table 5). Appropriate therapy was given in $77 \%$ of patients, and 105 number of cases classified under criteria IAS confirmatory laboratory reports were conducted to confirm the etiology. The cases falling under Criteria II (20.68\%) received empirical therapy with appropriate antimicrobial age, but culture sensitivity testing was not done to confirm the diagnosis. The cases falling under Criteria III were $10.91 \%$ as they received more than one antimicrobial agent concomitantly. $3.44 \%$ cases fall under Criteria IV as one patient was switched from injection cefotaxime to injection Augmentin, second patient from injection ampiclox to injection augmentin, third from injection ceftriaxone to injection augmentin, fourth injection augmentin to oral augmentin, fifth injection augmentin to oral amoxicillin, and sixth oral augmentin to intravenous augmentin. This shifting of AMAs is because the patients were not responding to treatment. $4.59 \%$ cases falling under Criteria $\mathrm{V}$ as the patients of viral infection received AMAs. According to Cochrane Database systemic review 2011, AMAs have a limited value in bronchiolitis [25]. However, in our study many of the patients of bronchiolitis received AMAs. 


\section{CONCLUSION}

Studying prescribing pattern help us facilitate the rational use of medicines and ensure the prudent use of available resources. As seen in our study antibacterials and respiratory medicines used judiciously, but cough and common cold preparations are used indiscriminately. There is a need for a standard treatment guideline for every hospital taking into account the local sensitivity pattern of organisms. There is a need for a standard treatment guideline for every hospital taking into account the local sensitivity pattern of organisms to confirm the appropriateness of AMAs. The present serves to highlight the current treatment of practice in our hospital

\section{ACKNOWLEDGMENT}

The author gave a special thanks to Dr. Deepti Jain mam, professor and Head of paediatrics for permission and valuable help in data collection from indoor patients.

\section{CONFLICTS OF INTEREST}

The authors declare that they have no conflicts of interest.

\section{REFERENCES}

1. Sanz EJ, Bergman U, Dahlstorm M. Paediatric drug prescribing. A comparison of Tenerife (Canary Islands, Spain) and Sweden. Eur J Clin Pharmacol 1989;37:65-8.

2. Summers RS, Summers B. Drug prescribing in paediatrics at a teaching hospital serving a developing community. Ann Trop Paediatr 1986;6:129-33.

3. Vashishtha VM. Current status of tuberculosis and acute respiratory infections in India: Much more needs to be done. Indian J Pediatr 2010;47:88-9.

4. Mohan S, Dharamraj K, Dindial R, Mathur D, Parmasad V, Ramdhanie J, et al. Physician behaviour for antimicrobial prescribing for pediatric URTI: A survey in general practice in Trinidad, West Indies. Ann Clin Microbiol Antimicrob 2004;3:11.

5. Wattal C, Goel N, Oberoi JK, Raveendran R, Datta S, Prasad KJ. Surveillance of multidrug resistant organisms in tertiary care hospital in Delhi, India. J Assoc Physicians India 2010;58 Suppl:32-6.

6. Sachdeva PD, Patel BG. Drug utilization studies-scope and future perspectives. Int J Pharm Biol Res 2010;1:11-6.

7. WHO. The Anatomical Therapeutic Chemical Classification System with Defined Daily Doses (ATC/DDD). Norway: WHO; 2004. Available from: http://www.who.int/classifications/actddd/en. [Last accessed on 2010 Oct 22]

8. Iyer GS, Patel PP, Panchal JR, Dikshit RK. An analysis of the pharmacological management of respiratory tract infections in pediatric in-patients at a tertiary care teaching hospital. Int J Med Public Health 2013;3:140-5.

9. Gajbhiye VP, Kale RS, Vilhekar KY, Bahekar SE. Drug utilization study on antimicrobials use in lower respiratory tract infection in
Pediatric Intensive Care Unit of Rural Tertiary Care Hospital. J Med Soc 2016;30:146-8.

10. Safaeian L, Mahdanian A, Hashemi-Fesharaki M, Salami S, KebriaeeZadeh J, Sadeghian G. General physicians and prescribing pattern in Isfahan, Iran. Oman Med J 2011;26:205-6.

11. Jose S, Rajashekarachar Y, Basavanthappa SP, Naidu BR. Evaluation of antibiotic usage on lower respiratory tract infections in paediatric department-an observational study. Int JContemp Pediatr 2016;3:146-49. Available from: www.ejmanager.com/mnstemps/119/119-1445084158. pdf. [Last cited on 2016 Oct 28].

12. Pasha SZ, Prasad BD, Shalem L, Chand TB, Veeramani G. Prescribing pattern and use of antibiotics and combination of antibiotics in a tertiary care teaching hospital. Indo Am J Pharm Res 2014;4:3172-81.

13. Shruthi KV, Bhandare B, Adarsh E. Prescribing pattern of drugs in paediatric in-patients with lower respiratory tract infection at a Tertiary care hospital. World J Pharm Pharm Sci 2016;5:2396-409.

14. WHO. How to Investigate Drug use in Health Facilities: Selected Drug use Indicators. WHO/DAP/93. Geneva: World Health Organization; 2010.

15. Triruthopu NS, Mateti UV, Bariri R, Sivva D, Martha S. Drug utilization pattern in south Indian paediatric population: A prospective study. Perspect Clin Res 2014;51:78-83

16. Deshmukh S, Mahajan M. A study of prescription pattern of antibiotics in paediatric in-patients at a tertiary care hospital in central. India Int $\mathbf{J}$ Pharmacol Res 2016;6:286-90.

17. Mohapatra S, Tripathy S, Balaji C, Rani RJ, Sekar P. Prescribing pattern of antimicrobial agents in pediatrics department of a teaching hospital. Int J Basic Clin Pharmacol 2015;4:753-6. Available from: http://dx.doi. org/10.18203/2319-2003.ijbcp20150385. [Last cited on 2016 Oct 28].

18. Arute JE, Adigom DO, Erach PO, Eichie EF, Eniojukan JF. Antibiotic prescription pattern in the paediatric ward of a tertiary health care facility in southern Nigeria. J Pharm Allied Sci 2011;8:34-42

19. Pramil T, Ahlawat R, Gupta G. Prescription practice in patients of upper respiratory tract infection at a pediatric outpatient clinic in Punjab. Indian J Pharm Pract 2014; 7:26-32

20. Kumar RS, Ray IM, Mohanty NC, Mukhia RK, Deshmukh YA. Assessment of usage of antibiotic and their pattern of antibiotic sensitivity test among childhood fever. Int J Pharm Pharm Sci 2014;6:296-9.

21. Kumar MA, Ramand KT, Ramasamy C. Cross sectional prospective study on drug utilization in an outpatient paediatric department of tertiary care teaching hospital. Glob J Pharmacol 2013;7:99-102.

22. Choudhury DK, Bezbaruah BK. Antibiotic prescriptions pattern in paediatric in-patient department. J Appl Pharm Sci 2013;3:144-8.

23. Satoskar RS, Rege N. Routes of administration and dosage. Pharmacology and Pharmacotherapeutics. 24 ${ }^{\text {th }}$ ed. India: Elsevier; 2015. p. 7

24. Vlahovic-Palcevski V, Francetic I, Palcevski G, Novak S, Abram M, Bergman U. Antimicrobial use at a university hospital: Appropriate or misused? A qualitative study. Int J Clin Pharmacol Ther 2007;45:169-74.

25. Spurling GK, Doust J, Del Mar CB, Eriksson L. Antibiotics for bronchiolitis in children. Cochrane Database Syst Rev 2011;15:CD005189. 